\title{
Fundamentals to clinical application of nanoparticles in cancer immunotherapy and radiotherapy
}

\author{
Vinodh Kumar Selvaraja (iD and Deleep Kumar Gudipudi iD \\ Department of Radiation Oncology, Basavatarakam Indo American Cancer Hospital and Research Institute, Road number 10, Banjara Hills, Hyderabad \\ 500034, Telangana, India \\ ahttps://orcid.org/0000-0002-2507-8328 \\ bhttps://orcid.org/0000-0003-3447-4725
}

\section{Abstract}

Cancer immunotherapy has made rapid progress over the past decade leading to high enthusiasm and interest worldwide. Codelivery of immunomodulators with chemotherapeutic agents and radioisotopes has been shown to elicit a strong and sustained immune response in animal models. Despite showing promising results in metastatic and recurrent cancers, the utilisation of immunotherapy in clinical settings has been limited owing to uncertainties in elicited immune response and occurrence of immune-related adverse events. These uncertainties can be overcome with the help of nanoparticles possessing unique properties for the effective delivery of targeted agents to specific sites. Nanoparticles play a crucial role in the effective delivery of cancer antigens and adjuvants, modulation of tumour microenvironment, production of long-term immune response and development of cancer vaccines. Here, we provide a comprehensive summary of nanotechnology-based cancer immunotherapy and radiotherapy including basics of nanotechnology, properties of nanoparticles and various methods of employing nanoparticles in cancer treatment. Thus, nanotechnology is anticipated to overcome the limitations of existing cancer immunotherapy and to effectively combine various cancer treatment modalities.

Keywords: nanoparticles, nanocarriers, cancer immunotherapy

\section{Introduction}

Cancer immunotherapy, which utilises the body's own immune system to fight against tumour cells, has grown in importance over the past decade. Novel strategies employed to enhance cytotoxic T-cell activation include chimeric antigen receptor T-cell therapy, immune checkpoint blockade (ICB) therapy and neoantigen vaccines [1-8]. Cancer immunotherapy has shown remarkable results in certain cancers which had poorer outcomes, especially in childhood acute lymphoblastic leukaemia, where CAR T-cell therapy targeting B-cell antigen (CD19) [9-13] led to an overall remission rate of $82.5 \%$ [14, 15], and in advanced melanoma, where cytotoxic T lymphocyte antigen 4 antibody improved the overall survival and 5 -year recurrence-free survival $[16,17]$. Compared to chemotherapy

Correspondence to: Vinodh Kumar Selvaraj Email: vinodhkumar.selva@gmail.com

ecancer 2020, 14:1095

https://doi.org/10.3332/ecancer.2020.1095

Published: 01/09/2020

Received: 31/12/2019

Publication costs for this article were supported by ecancer (UK Charity number 1176307).

Copyright: (c) the authors; licensee ecancermedicalscience. This is an Open Access article distributed under the terms of the Creative Commons Attribution License (http:// creativecommons.org/licenses/by/3.0), which permits unrestricted use, distribution, and reproduction in any medium, provided the original work is properly cited. 
and radiotherapy, immunotherapy confers greater and long-term benefits in recurrence or metastatic setting [18-20]. Despite promising results, the effect of immunotherapy in solid tumours is less pronounced [21,22] due to immunosuppressive tumour microenvironment and abnormal extracellular matrix created in cancer cells [23-25]. This is where biomaterial-based nanoparticles can play a crucial role in the effective delivery of immunotherapy.

\section{Fundamentals of nanoparticles}

Nanoparticles are nanoscale materials, usually made up of polymeric, liposomal and metallic formulations [26]. An ideal nanoparticle should be low-toxic, biodegradable, highly specific and cost effective [27]. Nanoparticles deliver the intended product to target sites by three methods: passive targeting, active targeting and physical targeting. Passive targeting is based on enhanced permeability and retention (EPR) effects, in which tumour cells selectively absorb nanoparticles, whereas, in active targeting, nanoparticles are coupled with ligands which interact with receptors over expressed in target sites. Physical targeting utilises the optical, thermal and magnetic properties of nanoparticles, where external sources guide them to reach the specific target sites [28].

\section{Basis of nanotechnology application in cancer treatment}

Nanotechnology-based drug delivery system has been utilised to enhance the efficacy of chemotherapy, radiotherapy and photodynamic therapy [29, 30]. The prime aim of using such systems is to enlarge the therapeutic window and the effective delivery of drugs [31]. Nanoformulations have shown improvement in a therapeutic window by acting at different levels of drug pharmacokinetics. The size of nanoformulations avoids renal clearance, and PEGylation prevents opsonisation by macrophages, thereby prolonging systemic circulation of drug [32]. The justification of cancer nanomedicine is based on the phenomenon called EPR effect [33]. The abnormal vasculature of tumour cells allows greater permeability, whereas the ineffective lymphatic clearance aids in the accumulation of nanoparticles inside tumour cells [34, 35]. Nanoparticles can also target cancer cells directly, either by coupling with a ligand and binding to the receptor of cancer cells (ligandreceptor complex) or by binding of surface moieties [36].

\section{Application of nanotechnology in cancer immunotherapy}

Nanotechnology used in cancer immunotherapy targets not only cancer cells but also lymphocytes and antigen-presenting cells (APCs) in circulation, thereby helping to generate a robust immune response. Hence, a much lower concentration of drug is needed when used in conjunct with immunomodulators [37]. In virtue of their high surface area to volume ratio, they are capable of carrying high-density peptide-major histocompatibility complex (pMHC), which, in turn, fastens the re-engagement of dissociated pMHC, and thereby delays the internalisation of T-cell receptors and prolongs the time for antigen presentation [38]. Therefore, the enhancement of cross-presentation of neoantigen to antigen-presenting cells leads to greater immune response. Nanotechnology can be used to intervene at various stages of cancer immunity cycle [39]. It can be used in the delivery of neoantigens for cancer vaccine development, delivery of adjuncts to increase immunogenicity, modulate tumour microenvironment, enhancement of immune recognition, delivery of checkpoint inhibitors and codelivery of checkpoint inhibitors with costimulatory immunomodulators, in adoptive immunotherapy and image-guided immunotherapy [40].

\section{Cancer nano-vaccines}

Cancer nanovaccines are designed for the effective delivery of tumour-derived protein antigens, or peptide antigens, or nucleic acid antigens to APCs, which, in turn, triggers an immune response [40]. Numerous research works are going on in the development of effective cancer nanovaccines. One group of researchers designed a sodium alginate-based formulations containing I-131-labelled catalases, which would transform into a hydrogel inside tumour cells in the presence of $\mathrm{Ca}^{2+}$ (calcium ion), and demonstrated a loading cytosine-guanine oligodeoxyneucleotide ( $\mathrm{CpG}$ ODN) with the radio-enhanced sodium alginate formulations resulted in strong systemic immune response [41]. 
Another group demonstrated the activation of dendritic cells, which depends on antigen association on nanoparticles and type of surfactants used. They reported absorption or encapsulation of antigens with nanoparticles, which increases expression of MHC Class II and MHC Class I, respectively, and observed a greater expression of CD86 by dendritic cells when nanoparticles are coated with polyvinyl alcohol (PVA) as surfactant rather than PF127. They concluded that the best antigen-specific T-cell response is produced with chitosan-mixed polylactide co-glycolide (PLGA) or polylactide co-glycolide block-polyethylene glycol (PLGA-b-PEG) formulation for ovalbumin antigens and CpG with PVA-coated, antigen-encapsulated nanoparticles [42].

Protein nanocarriers such as albumin-drug conjugates increase the half-life of drug in blood; potentiate draining to lymph nodes, enhance antigen presentation to APCs and thereby improve antitumour activity [40]. Abraxane is a nanodrug approved by the FDA, which is an albumin-paclitaxel conjugate used for advanced non-small cell lung cancer, metastatic pancreatic and breast cancer. Sahin et al. reported that the delivery of RNA-encoded antigens using DOTMA/DOPE liposomes led to a strong effector and memory T-cell responses along with IFN-alpha-mediated tumour rejection in animal models. A similar response was observed in their phase I trial too [43]. Nanovaccines can also be designed by coating natural cell membranes such as platelet membrane and leukocyte membrane onto a synthetic nanoparticulate core. The studies demonstrated that platelet membrane-coated nanoparticles selectively adhere to damaged vasculature and enhance binding to platelet-adhering pathogens, whereas leukocyte membrane-coated nanoparticles communicate with endothelial cells and transport payloads across inflamed reconstructed endothelium [44-46].

\section{Co-delivery of immune adjuvants}

Nanoparticles also help in the co-delivery of immune adjuvants along with antigens to avoid immune tolerance [29]. The commonly used adjuvants in cancer immunotherapy are lipopolysaccharide, 3-O-desacyl-4'-monophosphoryl lipid A (MPLA), Toll receptor agonists such as CpG oligodeoxynucleotides (ODNs) and polyinosinic:polycytidylic acid (poly I:C), agonists of the stimulator of IFN genes (STING) and cytokines (e.g., IL-2 and GM-CSF) [47]. Adjuvants such as CpG ODNs, STING and poly I:C are negatively charged, whereas nanoparticles

are positively charged, and hence, they form electrostatic complexes. By virtue of which, nanoparticles can aid in the effective delivery of these adjuvants into APCs along with tumour antigens, thereby promoting anticancer immune response [48, 49]. When the above mechanism is combined with ICB, there can be further enhanced anticancer immune response. A multifaceted immunomodulatory nanoliposomes developed by Lim group contain cancer membrane antigens to improve specificity towards tumour and two immunostimulatory adjuvants for immune stimulation such as MPLA and dimethyl dioctadecyl ammonium. This combination is denoted as tumosomes, which has shown to inhibit tumour growth and improve survival in mouse tumour models [50]. Nanoparticles can also deliver various anticancer therapeutic agents such as chemotherapy, immunotherapy and cell-based therapy to tumour sites, thereby improving therapeutic effect and minimising toxicity.

\section{Application of nanotechnology in cancer radiotherapy}

Radiotherapy has been a vital component of cancer treatment for several decades. With the advent of modern radiotherapy treatment machines and planning systems, the therapeutic ratio of radiotherapy has significantly improved. However, there still exist many challenges that hinder the effective treatment of cancer with radiotherapy. The major limitations of radiotherapy are hypoxic tumours, less radio responsive/radioresistant tumours, increased toxicity to adjacent normal structures and side effects while combining with chemotherapy and immunotherapy. These shortcomings of radiotherapy can be overcome with the help of nanotechnology.

\section{Radioisotope delivery by nanocarriers}

Radioisotopes used in radioimmunotherapy are broadly grouped into three categories based on the type of emitted particulate radiation. They are beta-emitters $\left({ }^{90} \mathrm{Y},{ }^{131} \mathrm{I},{ }^{199} \mathrm{Lu},{ }^{186} \mathrm{Rh},{ }^{89} \mathrm{Sr},{ }^{32} \mathrm{P}\right.$ and $\left.{ }^{67} \mathrm{Cu}\right)$, alpha emitters $\left({ }^{213} \mathrm{Bi},{ }^{221} \mathrm{At}\right.$ and $\left.{ }^{225} \mathrm{Ac}\right)$ and low-energy electron emitters $\left({ }^{125} \mathrm{I}\right.$,

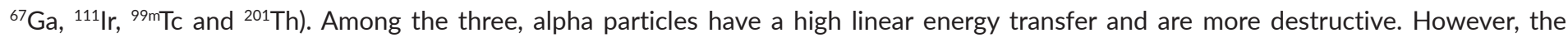
therapeutic effect of radioisotopes is largely hindered by rapid renal clearance due to smaller size ( $5 \mathrm{~nm}$ ) and opsonisation by mononuclear 
phagocyte system [51]. This problem is overcome by loading/conjugating radioisotopes to nanocarriers. Nanoparticles such as liposomes, micelles and polymeric complex decrease renal clearance owing to their increased size effect $(10 \mathrm{~nm})$ [52-55]. Furthermore, PEGylation of nanoparticles prevents the adsorption of opsonins due to steric hindrance produced by the presence of polyethylene glycol (PEG). Therefore, radioisotope-labelled nanoparticles significantly increase the short life of radioisotopes in blood. Wang et al [56] demonstrated that ${ }^{111} \mathrm{In}$ and ${ }^{177} \mathrm{Lu}$ PEGylated liposomes had a longer half-life in blood compared to ${ }^{111} \mathrm{n}$-DTPA in mice model. They also improve an intratumoural accumulation of radioisotopes through EPR effect and decrease the dose to surrounding normal structures, thereby improving therapeutic ratio [57, 58]. A PEGylated liposomal formulation of doxorubicin has a much slower clearance rate and an AUC 300 times greater than with free doxorubicin. It also proved to have greater intratumoural drug concentration and prolonged exposure time compared to free doxorubicin [59].

\section{Nanoformulations of radiosensitizers}

Hypoxia is a major deterrent of radiation effects on tumour cells $[60,61]$. Various strategies have been tried to overcome hypoxia and improve tumour cell kill to radiation, one among them is the usage of radiosensitizers [62]. Radiosensitizers are agents, which when used in conjunction with radiotherapy improve its lethal effects on tumour. An ideal hypoxic cell radiosensitizer must be chemically stable, highly soluble in water or lipids and more importantly selectively target tumour hypoxic cells sparing normal tissues. Various drugs of nitroimidazole group such as metronidazole, misonidazole, etanidazole and nimorazole have been tried as radiosensitizers [63]. Their efficacy as radiosensitizer is greatly reduced by dose-limiting toxicities and less solubility [65-67]. However, nanoformulations of radiosensitizers have shown to improve the effective delivery of these agents to tumour sites. In a study on mice model, nanoformulation of wortmannin (phosphatidylinositol 3' kinases \& related kinases inhibitor), composed of DSPE-PEG (1,2 distearoyl-sn-glycero-3-phosphoethanolamine - polyethylene glycol) lipid shell and PLGA polymer core, has shown to be more effective than 5FU as radiosensitizer [68]. Similarly, nanoformulations of histone deacetylase inhibitor has proved to be an effective radiosensitizer used in colorectal and prostate cancer cell lines [69, 70]. Nanoformulationbased radiosensitizers have a sustained DNA repair inhibition effect and achieve a lower concentration in normal tissues [70, 71].

In addition to acting as a carrier, few nanomaterials of high atomic number such as gold $(Z=79)$ and gadolinium $(Z=64)$ can act as potential radiosensitizers as dose absorbed by tissue is proportional to $Z^{2}$ of the material. The study by Zhang et al [72] demonstrated that tumour inhibition by radiotherapy can be significantly improved by using ultrasmall glutathione-coated gold nanoclusters as radiosensitizers. Combining radiation with gadolinium-based nanoparticles as radiosensitizers led to a significant tumour growth delay in a mouse model [73].

\section{Usage of nanoparticles to overcome radioresistance}

Radioresistance is another major factor leading to treatment failure after radiotherapy [74]. Apart from inherent less radiosensitivity of few tumours, it is the presence of hypoxia with central necrosis, expression of DNA repair enzymes and anti-apoptotic proteins that lead to radioresistance $[75,76]$. Nanotechnology helps in reducing radioresistance by targeting the related signalling pathways and genes. In the preclinical study on tumour-bearing mice model, the administration of bevacizumab 48 hours before radiotherapy led to the normalisation of tumour vasculature leading to temporary tumour reoxygenation and better radiosensitivity [77]. Another approach using nanoformulations of small interfering RNA (siRNA) and radiotherapy has shown to have encouraging results in overcoming radioresistance. On combining iron oxide nanoparticles coated with PEG and PEI to siRNA, LD50 of irradiation was reduced by threefold in medulloblastoma and ependymoma cells [78]. A similar combination of siRNA and PEG-PEI copolymer against sCLU protein drastically reduced cell survival after 0.5 and 3 Gy compared to radiotherapy alone group in breast cancer cells in vitro [79]. Zheng et al [80] recognised TRAF2 (TNF receptor-associated factor 2) as a potential target for siRNA silencing in glioblastoma cells, which led to radiosensitisation and tumour growth suppression.

\section{Nanotechnology to combine RT and other treatment modalities}

In the majority of locally advanced cancers, a multimodality treatment approach is advocated, especially chemoradiation [81]. Chemotherapy acts as a synergistic to radiotherapy and radiosensitizer [82]. However, the combination therapy leads to increased toxicity. Nanotechnology can help to alleviate this problem by the selective delivery of chemotherapeutic agents to tumour sites, thereby reducing toxicity during 
combination therapy. In addition to their synergistic effect, certain chemotherapeutic agents such as cisplatin, paclitaxel and doxorubicin also act as radiosensitizers [83-85]. In a tumour-bearing mice model, cisplatin delivered with upconversion nanoparticle led to enhanced effects by the release of both cisplatin and high metal ions [86]. The studies showed that the combination of chemotherapy and radiosensitizers in a single nanoparticle yields better chemotherapeutic effect than when loaded in separate nanoparticles. Au et al [87, 88] combined docetaxel and wortmannin in PLGA nanoparticle in an in vivo study and demonstrated that the toxicity profile of nanoparticle combined formulations had lesser hepatotoxicity and hematologic toxicity in comparison to the administration of each drug alone.

Another interesting prospect is targeted nanoparticle, in which the efficiency of nanoparticles is increased by surface modification of targeted ligands. Commonly targeted ligands are RGD peptide, folate and transferrin [89-91]. An in vivo study with docetaxel-loaded, folateconjugated nanoparticle showed that targeted nanoparticle is more efficient as radiosensitizer compared to nanoparticle without targeting ligands [92]. In a similar study, folate-targeted nanoparticle loaded with paclitaxel and yttrium-90 as a combination therapy proved to be superior in a murine model with ovarian cancer with peritoneal metastasis [93].

\section{Nanotechnology-based image-guided cancer immunotherapy and radiotherapy}

Image-guided cancer immunotherapy is another aspect of immunotherapy, where inorganic/metallic nanoparticles are used not only to deliver tumour antigens but also to provide imaging contrast for theranostics and immunogenic cell death through heat-induced or reactive oxygen species [94]. Researchers developed an iron oxide-zinc oxide core-shell nanoparticle, where the zinc oxide surface binds to certain peptide motifs with high binding affinity, whereas the iron oxide core provides imaging contrast for monitoring the migration of the nanovaccine as well as the activated DCs with magnetic resonance imaging (MRI) [95].

Gold nanoparticles have a multiple utility in cancer treatment such as signal enhancer for CT-guided radiotherapy, radiosensitizer and agents for photodynamic therapy [96, 97]. They are also used as CT contrast agents to assess the response to immunomodulators [98]. Poly $\mathrm{N}$-isopropyl acrylamide-coated gold nanoparticles in a gel matrix of sucrose acetate isobutyrate/EtOH/PLA (ethyl alcohol/polylactic acid) developed by Anderson et al [99] proved to be an excellent liquid fiducial tissue marker providing high-resolution micro-CT images in mice model for 2D X-ray visualisation. The same when used in canine cancer patient provided an enhanced image contrast for 2D X-ray and CT imaging with no side effects. In a mice model with intracerebral malignant gliomas, image-guided radiotherapy was delivered along with gold nanoparticles, where micro-CT images showed 19-fold higher intratumoural uptake of gold nanoparticles compared to normal brain [100].

Gold nanoparticles are also used as a part of nanocomposite, which contain two nanoparticles. Multimodal imaging with such nanocomposite can provide more information for accurate radiotherapy treatment delivery. In a tumour-bearing mice model, PCL-PEG micelle system loaded with SPIO and gold nanoparticles showed a selective accumulation in tumour and enhancement of tumour margins in MRI. Furthermore, the above nanocomposite improved 90-day survival rate [101]. Gold nanoparticles are also helpful in radiation in vivo dosimetry. Researchers developed a nanosensor composed of liquid surfactant-templated formation of coloured dispersions of gold nanoparticle, which can detect radiation dose from 0.5 to $2 \mathrm{~Gy}$. It provided the qualitative and quantitative assessment of radiation through the naked eye and absorbance spectrophotometer, respectively [102]. Nanosensors with upconversion nanoparticles and oxygen indicator have high sensitivity and specificity for the detection of oxygen changes in hypoxic environment and are useful in hypoxia imaging [103].

\section{Challenges and future directions}

After having successfully studied the properties and feasibilities of utilising nanoparticles in cancer immunotherapy through animal models, the biggest challenge lying ahead is translating these preclinical technologies into clinical practice. Clinical trials on combining immunotherapy and radiotherapy are already being conducted worldwide. Combining stereotactic body radiotherapy and nanoparticle-mediated dendritic cell activation resulting in ablation of tumour cells and nanoparticle-guided photodynamic therapy providing a high precision treatment are potential areas to be explored in the treatment of solid tumours. The other major roadblock is that we are yet to fully understand the toxicity profiles of nanoparticle-mediated immune response. It is unclear whether the codelivery of immunotherapeutic agents with chemoradiotherapy will result in intolerable side effects. Therefore, it is mandatory to study the toxicity profiles of nanoparticles and its 
modulation with various components of nanoformulations. With an improvement in understanding of cancer biology and cancer research, nanotechnology-based immunotherapy will change the treatment methodology and prognosis of advanced malignancies such as glioblastoma multiforme and pancreatic cancer in the near future.

\section{Conclusion}

With increasing global research on cancer immunology and biomedical engineering, the uncertainties surrounding combining nanoformulations of cancer immunotherapy and radiotherapy will be answered in the coming decade. Nanotechnology-based cancer immunotherapy and radiotherapy will soon turn out be a golden sword in the armory of every oncologist in the fight against cancer.

\section{Conflicts of interest}

There is no conflict of interest to declare.

\section{Author's contribution}

The first author (VKS) contributed in the conception of this review article, literature review and manuscript writing. The second author (DKG) contributed with his suggestions, proofreading and supervision.

\section{Funding statement}

No organisational grants or support was obtained for writing this manuscript.

\section{References}

1. Drake CG, Lipson EJ, and Brahmer JR (2014) Breathing new life into immunotherapy: review of melanoma, lung and kidney cancer Nat Rev Clin Oncol 11(1) 24-37 https://doi.org/10.1038/nrclinonc.2013.208 PMCID: 4086654

2. Melero I, Gaudernack G, and Gerritsen W, et al (2014) Therapeutic vaccines for cancer: an overview of clinical trials Nat Rev Clin Oncol 11(9) 509-524 https://doi.org/10.1038/nrclinonc.2014.111 PMID: 25001465

3. Gubin MM, Zhang X, and Schuster H, et al (2014) Checkpoint blockade cancer immunotherapy targets tumour-specific mutant antigens Nature 515 577-581 https://doi.org/10.1038/nature13988 PMID: 25428507 PMCID: 4279952

4. Melero I, Berman DM, and Aznar MA, et al (2015) Evolving synergistic combinations of targeted immunotherapies to combat cancer Nat Rev Cancer 15(8) 457-472 https://doi.org/10.1038/nrc3973 PMID: 26205340

5. Sharma P and Allison JP (2015) The future of immune checkpoint therapy Science 348(6230) 56-61 https://doi.org/10.1126/science. aaa8172 PMID: 25838373

6. Anagnostou VK and Brahmer JR (2015) Cancer immunotherapy: a future paradigm shift in the treatment of non-small cell lung cancer Clin Cancer Res 21(5) 976-984 https://doi.org/10.1158/1078-0432.CCR-14-1187 PMID: 25733707

7. Mellman I, Coukos G, and Dranoff G (2011) Cancer immunotherapy comes of age Nature 480 480-489 
8. Miller JF and Sadelain M (2015) The journey from discoveries in fundamental immunology to cancer immunotherapy Cancer Cell 27(4) 439-449 https://doi.org/10.1016/j.ccell.2015.03.007 PMID: 25858803

9. Jackson HJ, Rafiq S, and Brentjens RJ (2016) Driving CAR T-cells forward Nat Rev Clin Oncol 13(6) 370-383

10. Kochenderfer JN and Rosenberg SA (2013) Treating B-cell cancer with T cells expressing anti-CD19 chimeric antigen receptors Nat Rev Clin Oncol 10(5) 267-276 https://doi.org/10.1038/nrclinonc.2013.46 PMID: 23546520 PMCID: 6322669

11. Fesnak AD, June $\mathrm{CH}$, and Levine BL (2016) Engineered T cells: the promise and challenges of cancer immunotherapy Nat Rev Cancer 16(9) 566-581 https://doi.org/10.1038/nrc.2016.97 PMID: 27550819 PMCID: 5543811

12. Maude SL, Frey N, and Shaw PA, et al (2014) Chimeric antigen receptor T cells for sustained remissions in leukemia N Engl J Med 371(16) 1507-1517 https://doi.org/10.1056/NEJMoa1407222 PMID: 25317870 PMCID: 4267531

13. June CH and Sadelain M (2018) Chimeric antigen receptor therapy N Engl J Med 379(1) 64-73 https://doi.org/10.1056/NEJMra1706169 PMID: 29972754

14. Romero D. (2018) Haematological cancer: favourable outcomes with CAR T cells Nat Rev Clin Oncol 15(2) 65 https://doi.org/10.1038/ nrclinonc.2017.208 PMID: 29297506

15. Park JH, Geyer MB, and Brentjens RJ (2016) CD19-targeted CAR T-cell therapeutics for hematologic malignancies: interpreting clinical outcomes to date Blood 127(26) 3312-3320 https://doi.org/10.1182/blood-2016-02-629063 PMID: 27207800 PMCID: 4929923

16. Hodi FS, O'Day SJ, and McDermott DF, et al (2010) Improved survival with ipilimumab in patients with metastatic melanoma N Engl J Med 363(8) 711-723 https://doi.org/10.1056/NEJMoa1003466 PMID: 20525992 PMCID: 3549297

17. Eggermont AMM, Chiarion-Sileni V, and Grob JJ, et al (2016) Prolonged survival in stage III melanoma with ipilimumab adjuvant therapy N Engl J Med 375(19) 1845-1855 https://doi.org/10.1056/NEJMoa1611299 PMID: 27717298 PMCID: 5648545

18. Goldman A, Kulkarni A, and Kohandel M, et al (2016) Rationally designed 2-in-1 nanoparticles can overcome adaptive resistance in cancer ACS Nano 10(6) 5823-5834 https://doi.org/10.1021/acsnano.6b00320 PMID: 27257911

19. Shao K, Singha S, and Clemente-Casares X, et al (2014) Nanoparticle-based immunotherapy for cancer ACS Nano 9(1) 16-30 https://doi. org/10.1021/nn5062029 PMID: 25469470

20. Restifo NP, Smyth MJ, and Snyder A (2016) Acquired resistance to immunotherapy and future challenges Nat Rev Cancer 16(2) 121-126 https://doi.org/10.1038/nrc.2016.2 PMID: 26822578 PMCID: 6330026

21. Rosenberg SA, Restifo NP, and Yang JC, et al (2008) Adoptive cell transfer: a clinical path to effective cancer immunotherapy Nat Rev Cancer 8(4) 299-308 https://doi.org/10.1038/nrc2355 PMID: 18354418 PMCID: 2553205

22. Melero I, Rouzaut A, and Motz GT, et al (2014) T-cell and NK-cell infiltration into solid tumors: a key limiting factor for efficacious cancer immunotherapy Cancer Discov 4(5) 522-526 https://doi.org/10.1158/2159-8290.CD-13-0985 PMID: 24795012 PMCID: 4142435

23. Chen F, Zhuang X, and Lin L, et al (2015) New horizons in tumor microenvironment biology: challenges and opportunities BMC Med 13 45 https://doi.org/10.1186/s12916-015-0278-7 PMID: 25857315 PMCID: 4350882

24. Munn DH and Bronte V (2016) Immune suppressive mechanisms in the tumor microenvironment Curr Opin Immunol 39 1-6 https://doi. org/10.1016/j.coi.2015.10.009

25. Marvel D and Gabrilovich DI (2015) Myeloid-derived suppressor cells in the tumor microenvironment: expect the unexpected J Clin Invest 125(9) 3356-3364 https://doi.org/10.1172/JCI80005 PMID: 26168215 PMCID: 4588239

26. Min Y, Caster JM, and Eblan MJ, et al (2015) Clinical translation of nanomedicine Chem Rev 115(19) 11147-11190 https://doi. org/10.1021/acs.chemrev.5b00116 PMID: 26088284 PMCID: 4607605 
27. Poste G and Kirsh R (1983) Site-specific (targeted) drug delivery in cancer therapy Bio/Technology 1(10) 869-878 https://doi. org/10.1038/nbt1283-869

28. Bertrand N, Wu J, and Xu X, et al (2014) Cancer nanotechnology: the impact of passive and active targeting in the era of modern cancer biology Adv Drug Deliv Rev 66 2-25 https://doi.org/10.1016/j.addr.2013.11.009 PMCID: 4219254

29. Peer D, Karp JM, and Hong S, et al (2007) Nanocarriers as an emerging platform for cancer therapy Nat Nanotechnol 2(21) 751-760 https://doi.org/10.1038/nnano.2007.387

30. Kemp JA, Shim MS, and Heo CY, et al (2016) "Combo" nanomedicine: co-delivery of multi-modal therapeutics for efficient, targeted, and safe cancer therapy Adv Drug Deliv Rev 98 3-18 https://doi.org/10.1016/j.addr.2015.10.019

31. Kim BYS, Rutka JT, and Chan WCW (2010) Nanomedicine N Engl J Med 363(25) 2434-2443 https://doi.org/10.1056/NEJMra0912273 PMID: 21158659

32. Goldberg MS (2015) Immunoengineering: how nanotechnology can enhance cancer immunotherapy Cell 161(2) 201-204 https://doi. org/10.1016/j.cell.2015.03.037 PMID: 25860604

33. Maeda H, Sawa T, and Konno T (2010) Mechanism of tumor-targeted delivery of macromolecular drugs, including the EPR effect in solid tumor and clinical overview of the prototype polymeric drug SMANCS J Control Release 74(1-3) 47-61 https://doi.org/10.1016/ S0168-3659(01)00309-1

34. Yuan F, Dellian M, and Fukumura D, et al (1995) Vascular permeability in a human tumor xenograft: molecular size dependence and cutoff size Cancer Res 55(17) 3752-3756 PMID: 7641188

35. Thomas SN, Vokali E, and Lund AW, et al (2014) Targeting the tumor-draining lymph node with adjuvanted nanoparticles reshapes the anti-tumor immune response Biomaterials 35(2) 814-824 https://doi.org/10.1016/j.biomaterials.2013.10.003

36. Jiang W, von Roemeling CA, and Chen Y, et al (2017) Designing nanomedicine for immuno-oncology Nat Biomed Eng 1(2) 0029 https:// doi.org/10.1038/s41551-017-0029

37. Wang $\mathrm{C}, \mathrm{Ye} \mathrm{Y}$, and $\mathrm{Hu}$ Q, et al (2017) Tailoring biomaterials for cancer immunotherapy: emerging trends and future outlook Adv Mater 29(29) 1606036 https://doi.org/10.1002/adma.201606036

38. Huppa JB, Axmann M, and Mortelmaier MA, et al (2010) TCR-peptide-MHC interactions in situ show accelerated kinetics and increased affinity Nature 463(7283) 963-967 https://doi.org/10.1038/nature08746 PMID: 20164930 PMCID: 3273423

39. Hartshorn CM, Bradbury MS, and Lanza GM, et al (2018) Nanotechnology strategies to advance outcomes in clinical cancer care ACS Nano 12(1) 24-43 https://doi.org/10.1021/acsnano.7b05108

40. Yu Mi, Hagan CT 4th, and Vincent BG, et al (2019) Emerging nano-/microapproaches for cancer immunotherapy Adv Sci 6(6) 1801847 https://doi.org/10.1002/advs.201801847

41. Chao Y, Xu L, and Liang C, et al (2018) Combined local immunostimulatory radioisotope therapy and systemic immune checkpoint blockade imparts potent antitumour responses Nat Biomed Eng 2(8) 611-621 https://doi.org/10.1038/s41551-018-0262-6

42. Zupancic E, Curato C, and Paisana M, et al (2017) Rational design of nanoparticles towards targeting antigen-presenting cells and improved T cell priming J Control Release 258 182-195 https://doi.org/10.1016/j.jconrel.2017.05.014 PMID: 28511928

43. Kranz LM, Diken M, and Haas $\mathrm{H}$, et al (2016) Systemic RNA delivery to dendritic cell exploits antiviral defense for cancer immunotherapy Nature 534 396-401 https://doi.org/10.1038/nature18300 PMID: 27281205

44. Hu CM, Fang RH, and Wang KC, et al (2015) Nanoparticle biointerfacing by platelet membrane cloaking Nature 526 118-121 https:// doi.org/10.1038/nature15373 PMID: 26374997 PMCID: 4871317 
45. Parodi A, Quattrocchi N, and van de Ven AL, et al (2012) Synthetic nanoparticles functionalized with biomimetic leukocyte membranes possess cell-like functions Nat Nanotechnol 8 61-68 https://doi.org/10.1038/nnano.2012.212 PMID: 23241654 PMCID: 3751189

46. Wang Q, Ren Y, and Mu J, et al (2015) Grapefruit-derived nanovectors use an activated leukocyte trafficking pathway to deliver therapeutic agents to inflammatory tumor aites Cancer Res 75(12) 2520 https://doi.org/10.1158/0008-5472.CAN-14-3095 PMID: 25883092 PMCID: 4470740

47. Hu Z, Ott PA, and Wu CJ (2018) Towards personalized, tumour-specific, therapeutic vaccines for cancer Nat Rev Immunol 18(3) 168 https://doi.org/10.1038/nri.2017.131

48. Chen S, Zhang H, and Shi X, et al (2014) Microfluidic generation of chitosan/CpG oligodeoxynucleotide nanoparticles with enhanced cellular uptake and immunostimulatory properties Lab Chip 14(11) 1842-1849 https://doi.org/10.1039/c4lc00015c PMID: 24733088

49. Luo M, Wang H, and Wang Z, et al (2017) A STING-activating nanovaccine for cancer immunotherapy Nat Nanotechnol 12(7) 648-654 https://doi.org/10.1038/nnano.2017.52 PMID: 28436963 PMCID: 5500418

50. Noh YW, Kim SY, and Kim JE, et al (2017) Multifaceted immunomodulatory nanoliposomes: reshaping tumors into vaccines for enhanced cancer immunotherapy Adv Funct Mater 27(8) 1605398 https://doi.org/10.1002/adfm.201605398

51. Mi Y, Shao Z, and Vang J, et al (2016) Application of nanotechnology to cancer radiotherapy Cancer Nanotechnol 7(1) 11 https://doi. org/10.1186/s12645-016-0024-7

52. Brigger I, Dubernet C, and Couvreur P (2002) Nanoparticles in cancer therapy and diagnosis Adv Drug Deliv Rev 54(5) 631-651 https:// doi.org/10.1016/S0169-409X(02)00044-3 PMID: 12204596

53. Davis ME, Chen ZG, and Shin DM (2008) Nanoparticle therapeutics: an emerging treatment modality for cancer Nat Rev Drug Discov 7(9) 771-782 https://doi.org/10.1038/nrd2614 PMID: 18758474

54. Feng SS, Zhao LY, and Zhang ZP, et al (2007) Chemotherapeutic engineering: vitamin E TPGS-emulsified nanoparticles of biodegradable polymers realized sustainable paclitaxel chemotherapy for $168 \mathrm{~h}$ in vivo Chem Eng Sci 62(23) 6641-6648 https://doi.org/10.1016/j. ces.2007.08.006

55. Kim BY, Rutka JT, and Chan WC (2010) Nanomedicine N Engl J Med 363(25) 2434-2443 https://doi.org/10.1056/NEJMra0912273 PMID: 21158659

56. Wang HE, Yu HM, and Lu YC, et al (2006) Internal radiotherapy and dosimetric study for 111In/177Lu-pegylated liposomes conjugates in tumor-bearing mice Nucl Instrum Methods Phys Res Sect A 569(2) 533-537 https://doi.org/10.1016/j.nima.2006.08.124

57. Fang J, Nakamura $\mathrm{H}$, and Maeda $\mathrm{H}$ (2011) The EPR effect: unique features of tumor blood vessels for drug delivery, factors involved, and limitations and augmentation of the effect Adv Drug Deliv Rev 63(3) 136-151 https://doi.org/10.1016/j.addr.2010.04.009

58. Maeda H, Wu J, and Sawa T, et al (2000) Tumor vascular permeability and the EPR effect in macromolecular therapeutics: a review J Control Release 65(1-2) 271-284 https://doi.org/10.1016/S0168-3659(99)00248-5 PMID: 10699287

59. Barenholz Y. (2012) Doxil(R)-the first FDA-approved nano-drug: lessons learned J Control Release 160(2) 117-134 https://doi. org/10.1016/j.jconrel.2012.03.020 PMID: 22484195

60. Brizel DM, Sibley GS, and Prosnitz LR, et al (1997) Tumor hypoxia adversely affects the prognosis of carcinoma of the head and neck Int J Radiat Oncol Biol Phys 38(2) 285-289 https://doi.org/10.1016/S0360-3016(97)00101-6 PMID: 9226314

61. Koukourakis MI, Bentzen SM and Giatromanolaki A, et al (2006) Endogenous markers of two separate hypoxia response pathways (hypoxia inducible factor 2 alpha and carbonic anhydrase 9) are associated with radiotherapy failure in head and neck cancer patients recruited in the CHART randomized trial J Clin Oncol 24(5) 727-735 https://doi.org/10.1200/JC0.2005.02.7474 PMID: 16418497 
62. Overgaard J and Horsman MR (1996) Modification of hypoxia-induced radioresistance in tumors by the use of oxygen and sensitizers Semin Radiat Oncol 6(1) 10-21 https://doi.org/10.1016/S1053-4296(96)80032-4 PMID: 10717158

63. Overgaard J (1994) Clinical evaluation of nitroimidazoles as modifiers of hypoxia in solid tumors Oncol Res 6(10-11) 509-518 PMID: 7620219

64. Overgaard J, Sand Hansen H, and Andersen AP, et al (1989) Misonidazole combined with split-course radiotherapy in the treatment of invasive carcinoma of larynx and pharynx: report from the DAHANCA 2 study Int J Radiat Oncol Biol Phys 16(4) 1065-1068 https://doi. org/10.1016/0360-3016(89)90917-6 PMID: 2649462

65. Overgaard J, Sand Hansen H, and Lindelov B, et al (1991) Nimorazole as a hypoxic radiosensitizer in the treatment of supraglottic larynx and pharynx carcinoma. First report from the Danish Head and Neck Cancer Study (DAHANCA) protocol 5-85 Radiother Oncol 20 143-149 https://doi.org/10.1016/0167-8140(91)90202-R

66. Overgaard J, Sand Hansen H, and Overgaard M, et al (1992) The Danish Head and Neck Cancer Study Group (DAHANCA) randomized trials with hypoxic radiosensitizers in carcinoma of the larynx and pharynx Radiation research: a twentieth-century perspective vol II, eds WC Dewey, M Eddington, and RJM Fry et al (New York: Academic Press) pp 573-577

67. Karve S, Werner ME, and Sukumar R, et al (2012) Revival of the abandoned therapeutic wortmannin by nanoparticle drug delivery Proc Natl Acad Sci USA 109(21) 8230-8235 https://doi.org/10.1073/pnas.1120508109 PMID: 22547809 PMCID: 3361429

68. Tian X, Lara H, and Wagner KT, et al (2015) Improving DNA double-strand repair inhibitor KU55933 therapeutic index in cancer radiotherapy using nanoparticle drug delivery Nanoscale 7(47) 20211-20219 https://doi.org/10.1039/C5NR05869D PMID: 26575637 PMCID: 4664156

69. Faltmark K, Nome VR, and Folkvard S, et al (2006) Radiosensitization of colorectal carcinoma cell lines by histone deacetylase inhibitor Radiat Oncol 125 https://doi.org/10.1186/1748-717X-1-25

70. Frame FM, Pellacani D, and Collins AT, et al (2013) HDAC inhibitor confers radiosensitivity to prostate stem-like cells Br J Cancer 109(12) 3023-3033 https://doi.org/10.1038/bjc.2013.691 PMID: 24220693 PMCID: 3859953

71. Wang EC, Min Y, and Palm RC, et al (2015) Nanoparticle formulations of histone deacetylase inhibitors for effective chemoradiotherapy in solid tumors Biomaterials 51 208-215 https://doi.org/10.1016/j.biomaterials.2015.02.015 PMID: 25771011 PMCID: 4361776

72. Zhang XD, Luo Z, and Chen J, et al (2015) Ultrasmall glutathione-protected gold nanoclusters as next generation radiotherapy sensitizers with high tumor uptake and high renal clearance Sci Rep 58669 https://doi.org/10.1038/srep08669 PMID: 25727895 PMCID: 4345316

73. Miladi I, Aloy MT, and Armandy E, et al (2015) Combining ultrasmall gadolinium-based nanoparticles with photon irradiation overcomes radioresistance of head and neck squamous cell carcinoma Nanomedicine 11(1) 247-257 https://doi.org/10.1016/j.nano.2014.06.013

74. Perri F, Pacelli R, and Della Vittoria Scarpatti, et al (2015) Radioresistance in head and neck squamous cell carcinoma: biological bases and therapeutic implications Head Neck 37(5) 763-770 https://doi.org/10.1002/hed.23837

75. Al-Dimassi S, Abou-Antoun T, and El-Sibai M (2014) Cancer cell resistance mechanisms: a mini review Clin Transl Oncol 16(6) 511-516 https://doi.org/10.1007/s12094-014-1162-1 PMID: 24647842

76. Zhao J, Mi Y, and Feng SS (2013) siRNA-based nanomedicine Nanomedicine 8(6) 859-862 https://doi.org/10.2217/nnm.13.73 PMID: 23730692

77. Carmeliet $P$ and Jain RK (2011) Principles and mechanisms of vessel normalization for cancer and other angiogenic diseases Nat Rev Drug Discov 10(6) 417-427 https://doi.org/10.1038/nrd3455 PMID: 21629292

78. Kievit FM, Stephen ZR, and Wang K, et al (2015) Nanoparticle mediated silencing of DNA repair sensitizes pediatric brain tumor cells to gamma-irradiation Mol Oncol 9(6) 1071-1080 https://doi.org/10.1016/j.molonc.2015.01.006 PMID: 25681012 PMCID: 4439369 
79. Sutton D, Kim S, and Shuai X, et al (2006) Efficient suppression of secretory clusterin levels by polymer-siRNA nanocomplexes enhances ionizing radiation lethality in human MCF-7 breast cancer cells in vitro Int J Nanomed 1(2) 155-162 https://doi.org/10.2147/ nano.2006.1.2.155

80. Zheng M, Morgan-Lappe SE, and Yang J, et al (2008) Growth inhibition and radiosensitization of glioblastoma and lung cancer cells by small interfering RNA silencing of tumor necrosis factor receptor associated factor 2 Cancer Res 68(18) 7570-7578 https://doi. org/10.1158/0008-5472.CAN-08-0632 PMID: 18794145 PMCID: 2597026

81. Blanchard P, Baujat B, and Holostenco V, et al (2011) Meta-analysis of chemotherapy in head and neck cancer (MACH-NC): a comprehensive analysis by tumour site Radiother Oncol 100(1) 33-40 https://doi.org/10.1016/j.radonc.2011.05.036 PMID: 21684027

82. Lawrence TS, Haffty BG, and Harris JR (2014) Milestones in the use of combined-modality radiation therapy and chemotherapy J Clin Oncol 32(12) 1173-1179 https://doi.org/10.1200/JCO.2014.55.2281 PMID: 24663053

83. Jung J, Park SJ, and Chung HK, et al (2012) Polymeric nanoparticles containing taxanes enhance chemoradiotherapeutic efficacy in non-small cell lung cancer Int J Radiat Oncol Biol Phys 84(1) e77-e83 https://doi.org/10.1016/j.ijrobp.2012.02.030 PMID: 22795728

84. Werner ME, Cummings ND, and Sethi M, et al (2013) Preclinical evaluation of Genexol-PM, a nanoparticle formulation of paclitaxel, as a novel radiosensitizer for the treatment of non-small cell lung cancer Int J Radiat Oncol Biol Phys 86(3) 463-468 https://doi. org/10.1016/j.ijrobp.2013.02.009 PMID: 23708084 PMCID: $\underline{3750707}$

85. Xiong H, Zhou D, and Qi Y, et al (2015) Doxorubicin-loaded carborane-conjugated polymeric nanoparticles as delivery system for combination cancer therapy Biomacromolecules 16(12) 3980-3988 https://doi.org/10.1021/acs.biomac.5b01311 PMID: 26564472

86. Fan W, Shen B, and Bu W, et al (2013) Rattle-structured multifunctional nanotheranostics for synergetic chemo-/radiotherapy and simultaneous magnetic/luminescent dual-mode imaging J Am Chem Soc 135(17) 6494-6503 https://doi.org/10.1021/ja312225b PMID: 23574400

87. Au KM, Hyder SN, and Wagner K, et al (2015) Direct observation of early-stage high-dose radiotherapy induced vascular injury via basement membrane-targeting nanoparticles Small 11(48) 6404-6410 https://doi.org/10.1002/smll.201501902 PMID: 26577747 PMCID: 4813349

88. Au KM, Min Y, and Tian X, et al (2015) Improving cancer chemoradiotherapy treatment by dual controlled release of wortmannin and docetaxel in polymeric nanoparticles ACS Nano 9(9) 8976-8996 https://doi.org/10.1021/acsnano.5b02913 PMID: 26267360 PMCID: 4990743

89. Mi Y, Liu Y, and Feng SS (2011) Formulation of docetaxel by folic acid-conjugated d-a-tocopheryl polyethylene glycol succinate 2000 (Vitamin E TPGS(2k)) micelles for targeted and synergistic chemotherapy Biomaterials 32(16) 4058-4066 https://doi.org/10.1016/j. biomaterials.2011.02.022 PMID: 21396707

90. Mi Y, Liu Y, and Guo Y, et al (2011) Herceptin(R)-conjugated nanocarriers for targeted imaging and treatment of HER2-positive cancer Nanomedicine 6(2) 311-312 https://doi.org/10.2217/nnm.11.1 PMID: 21385133

91. Zhao J, Mi Y, and Liu Y, et al (2012) Quantitative control of targeting effect of anticancer drugs formulated by ligand conjugated nanoparticles of biodegradable copolymer blend Biomaterials 33(6) 1948-1958 https://doi.org/10.1016/j.biomaterials.2011.11.051

92. Werner ME, Copp JA, and Karve S, et al (2011a) Folate-targeted polymeric nanoparticle formulation of docetaxel is an effective molecularly targeted radiosensitizer with efficacy dependent on the timing of radiotherapy ACS Nano 5(11) 8990-8998 https://doi. org/10.1021/nn203165z

93. Werner ME, Cummings ND, and Sethi M, et al (2013) Preclinical evaluation of Genexol-PM, a nanoparticle formulation of paclitaxel, as a novel radiosensitizer for the treatment of non-small cell lung cancer Int J Radiat Oncol Biol Phys 86(3) 463-468 https://doi. org/10.1016/j.ijrobp.2013.02.009 PMID: 23708084 PMCID: 3750707 
94. Shevtsov MA, Nikolaev BP, and Yakovleva LY, et al (2015) 70-kDa heat shock protein coated magnetic nanocarriers as a nanovaccine for induction of anti-tumor immune response in experimental glioma J Control Release 220(Pt A) 329-340 https://doi.org/10.1016/j. jconrel.2015.10.051 PMID: 26522072

95. Cho NH, Cheong TC, and Min JH, et al (2011) A multifunctional core-shell nanoparticle for dendritic cell-based cancer immunotherapy Nat Nanotechnol 6(10) 675-682 https://doi.org/10.1038/nnano.2011.149 PMID: 21909083

96. Dykman L and Khlebtsov N (2012) Gold nanoparticles in biomedical applications: recent advances and perspectives Chem Soc Rev 41(6) 2256-2282 https://doi.org/10.1039/C1CS15166E

97. Zhang X. (2015) Gold nanoparticles: recent advances in the biomedical applications Cell Biochem Biophys 72(3) 771-775 https://doi. org/10.1007/s12013-015-0529-4 PMID: 25663504

98. Meir R, Shamalov K, and Sadan T, et al (2017) Fast image-guided stratification using anti-programmed death ligand 1 gold nanoparticles for cancer immunotherapy ACS Nano 11(11) 11127-11134 https://doi.org/10.1021/acsnano.7b05299 PMID: 29028305

99. Jolck RI, Rydhog JS, and Christensen AN, et al (2015) Injectable colloidal gold for use in intrafractional 2D image-guided radiation therapy Adv Healthc Mater 4(6) 856-863 https://doi.org/10.1002/adhm.201400651 PMID: 25607532

100. Hainfeld JF, Smilowitz HM, and O'Connor MJ, et al (2013) Gold nanoparticle imaging and radiotherapy of brain tumors in mice Nanomedicine 8(10) 1601-1609 https://doi.org/10.2217/nnm.12.165

101.McQuade C, Al Zaki A, and Desai Y, et al (2015) A multifunctional nanoplatform for imaging, radiotherapy, and the prediction of therapeutic response Small 11(7) 834-843 https://doi.org/10.1002/smll.201401927 PMCID: 4329028

102.Pushpavanam K, Narayanan E, and Chang J, et al (2015) A colorimetric plasmonic nanosensor for dosimetry of therapeutic levels of ionizing radiation ACS Nano 9(12) 11540-11550 https://doi.org/10.1021/acsnano.5b05113 PMID: 26434692

103. Liu J, Liu Y, and Bu W, et al (2014) Ultrasensitive nanosensors based on upconversion nanoparticles for selective hypoxia imaging in vivo upon near-infrared excitation J Am Chem Soc 136(27) 9701-9709 https://doi.org/10.1021/ja5042989 PMID: 24956326 